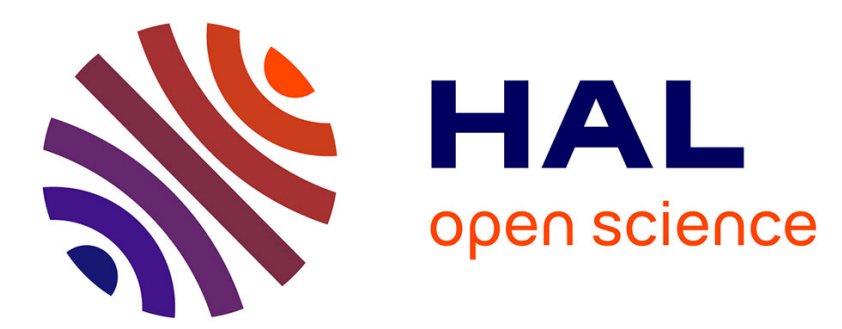

\title{
DYNAMIC TOUGHNESS OF FRACTURE AND A COLD RESISTANCE OF WELD JOINTS
}

\author{
A. Ammosov, V. Larionov
}

\section{To cite this version:}

A. Ammosov, V. Larionov. DYNAMIC TOUGHNESS OF FRACTURE AND A COLD RESISTANCE OF WELD JOINTS. Journal de Physique IV Proceedings, 1991, 01 (C3), pp.C3-171-C3-176. 10.1051/jp4:1991322 . jpa-00250464

\section{HAL Id: jpa-00250464 https://hal.science/jpa-00250464}

Submitted on 1 Jan 1991

HAL is a multi-disciplinary open access archive for the deposit and dissemination of scientific research documents, whether they are published or not. The documents may come from teaching and research institutions in France or abroad, or from public or private research centers.
L'archive ouverte pluridisciplinaire HAL, est destinée au dépôt et à la diffusion de documents scientifiques de niveau recherche, publiés ou non, émanant des établissements d'enseignement et de recherche français ou étrangers, des laboratoires publics ou privés. 
Colloque C3, suppl. au Journal de Physique III, Vol. 1, octobre 1991

\title{
DYNAMIC TOUGHNESS OF FRACTURE AND A COLD RESISTANCE OF WELD JOINTS
}

\author{
A.P. AMMOSOV and V.P. LARIONOV
}

Institute of Physical-Technical Problems of the North, YSC, SO AN SSSR, Oktyabrskaya street 1, 677891 Yakutsk, USSR

\begin{abstract}
Résumé:La méthode proposée consiste à déterminer la valeur limite de la tenacité dynamique $\mathrm{K}^{\mathrm{min}}$ et la vitesse de propagation maximum de fissures fragiles $\mathrm{V}^{\max }$. dans un essai standard. On montre la possibilité à partir des valeurs de $K$ et $V$ et de la connaissance de la distribution statistique des indices fractographiques de la surface de fracture fragile. La conclusion est que les critères $\mathrm{K}^{\mathrm{min}}$ et $\mathrm{V}^{\max }$ peuvent être efficacement utilisés pour estimer la résistance à froid des joints soudés.
\end{abstract}

\section{ABSTRACT}

The proposed method seeks to determine the limiting value of the dynamic fracture toughness $\mathrm{k}_{\mathrm{IA}}^{\mathrm{min}}$ and maximum rate of the brittle crack propagation $V_{B r}^{\max }$ in standard specimen testing. There is shown the possibility to estimate them using $\overline{\mathrm{K}}_{\mathrm{IA}}$ and $\overline{\mathrm{V}}_{\mathrm{B}} \mathrm{values}$ and character knowledge of statistical distribution of the fractographical indeces of the brittle fracture surface. The conclusion is that the $K_{1 A}^{m i n}$ and $v_{b r}^{\max }$ criteria can be effectively used in estimation of the weld joint cold resistance.

THE CONTENT OF THE WORK

The main assessment criterion of steels cold resistance and their weld joints in dynamic loading is spesific fracture energy a of a specimen with a crack (according to [1] and All-Union Standard 9454-78) and also $K_{i C}^{A}$ and $K_{C}^{A}$; using the concentrators of $U$ and $V$ type the criteria are $\mathrm{KCU}, \mathrm{KCV}, \mathrm{KCU}_{\mathrm{or}}, \mathrm{KCV}_{\mathrm{Or}}$, and also $\mathrm{KCU}_{\mathrm{p}}$ and $\mathrm{KCV}_{\mathrm{p}}$ : Lowering the specimen test temperature at the same values of stored energy during a shock loading results in decrease of material resistance to the brittle crack propagation and hence leads to increase of its propagation rate. The stress intensity factors $K_{i c}^{A}$ and $K_{c}^{A}$ are the criteria of fracture toughness that determine the cracking resistance of the material at the moment the crack is starting to move during a dynamic (shock) loading of a specimen, and therefore they cannot be used in analyzing the limit values of dynamic fracture toughness when a brittle crack is propagating in materials.

In this paper there is considered a method to determine the limit values of dynamic fracture toughness $K_{1 A}^{p}$ and $v_{b r}^{p}$. using the strain diagram and the data of the fractographic indeces of the specimen brittle fracture surface. The application of $\mathrm{K}_{\mathrm{A}}^{\mathrm{A}}$ and $\mathrm{V}_{\mathrm{br}}^{\mathrm{p}}$ to estimation of the weld joints cold resistance for metalwork units and Northern machinery is substantiated by the authors.

Within the framework of the linear fracture mechanics model for a crack with normal breaking-off the authors[2] of this article have work- 
ed out the method to determine the critical factor of stress intensity $\mathrm{K}_{1 A}$ by relation to crack propagation rate and test temperature. The method is based on the estimation of the work expended on a brittle crack propagation using an oscillography procedure to record a fracture process in terms of coordinates "force-time" (fig.1) and can be applied to the shock loading of any type if a fracture process oscillography is available.

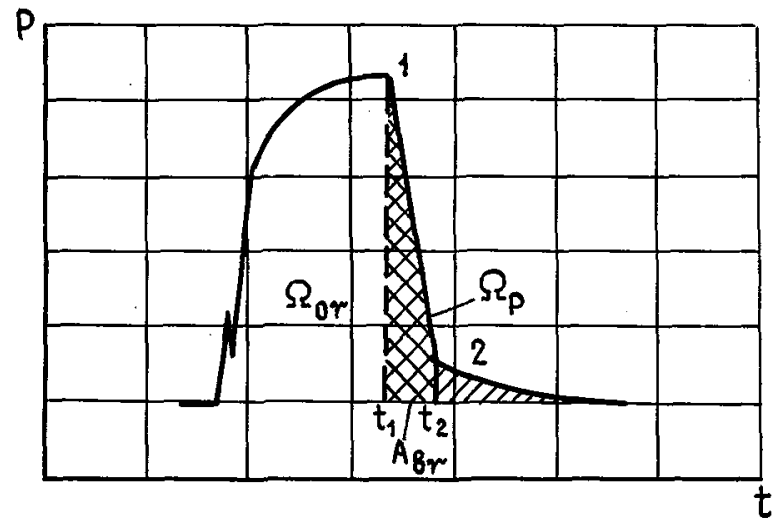

Fig.1. The typical oscillogram of the specimen fracture process: $\Omega$ or , $\Omega p$ - areas corresponding to the works of crack origination and propagation; $t_{1} 12 t_{2}\left(\Omega_{\mathrm{Br}}\right)$ - area corresponding to the energy $\left(A_{\mathrm{br}}\right.$. ' expended on the brittle crack propagation.

A rapid decrease of a fracture load at sections 1 and 2 (fig.1) is caused by the brittle crack movement; and the area underneath the curve at this section characterizes the work $A_{\text {pr }}$ expended on the crack progress and can be estimated by the formula[3]:

$$
A_{b r}=\left\{V_{0}-\frac{L}{l_{\text {red }}} \cdot \frac{q}{F}\left[\int_{0}^{t_{1}} P(t) d t-\frac{1}{2} \int_{t_{1}}^{t_{2}} P(t) d t\right]\right\} \int_{t_{1}}^{t_{2}} P(t) d t
$$

where $I$ - distance from the pendulum axis to collision point; $I_{\text {red }}$ reduced pendulum length; $q$ - gravity; $F$ - necessary force for horizontal pendulum equilibration that is applied to the pendulum face at $\mathrm{L}-$ distance from its axis; $t_{1}$ - start of a brittle crack movement; $t_{2}-\mathrm{a}$ brittle crack stop. Complexity of $A_{b r}$ determination consists in reaching the high accuracy in estimating the oscillogram area $\Omega_{b r}$ (fig.1) corresponding to the brittle crack propagation. Computer science application is the most effective in this case.

The $K_{1 A}$ value is determined by the relation $K_{1 A}^{2}=E_{1 A} /\left(1-\mu^{2}\right)$ [2]; where $E$ - elastic modulus; $\mu$ - Puasson factor; $\mathrm{G}_{1 A}$ - energy release intensity during a crack propagation of a break-off type that is equal to the ultimate work necessary to form a brittle crack of a unit area i.e. $G_{I_{A}}=A_{b r} / F_{\text {pr. }}$. The brittle crack area, $F_{b r}$, with clear boundaries for fow-alloyed steels and their weld joints; and the brittle crack length, $I_{\text {br }}$, are measured after the specimen destruction. The mean rate $\left(\bar{\nabla}_{\text {br. }}\right)^{\text {of }}$ the brittle crack propagation can be estimated on the basis of crack propagation time, equal to $t_{2}-t_{1}$, and the length $1_{\mathrm{br} .}[2]$. 
Within the framework of the given model there is established a relation between $K_{1 A}$ and $\overline{\mathrm{V}}_{b r}$. (rate of brittle crack propagation), fig. 2 . The obtained relationship can be written down as a function $\overline{\mathrm{K}}_{1 \mathrm{~A}}=\mathrm{A} / \overline{\mathrm{V}}_{\mathrm{br}}$, where $A$ and $B$ are constants. Consequently, as the propagation rate of a brittle crack increases the dynamic factor of stress intensity dec reases. To reach the precise values of $A$ and $B$ one should refine the limit values of $K_{i A}^{p}$ and $v_{b r}^{P}$. representing the functions $K_{A A}^{P}=f_{1}\left(I_{b r}\right)$ and $\mathrm{V}_{\mathrm{br}}^{\mathrm{P}}=\mathrm{f}_{2}\left(1_{\mathrm{br}}\right)$.

The energy release intensity during the crack propagation of a breakoff type $G_{1 A}$, equal to the ultimate work, that is necessary to form a brittle crack of a unit area, is based on the supposition that $A_{b r}$ is equally distributed over the whole fracture surface ( $\left.F_{b r}\right)$, i.e.it is assumed that energy intensity of the separate sections of brittle fra cture surface is the same. As a result of this assumption the dynamic factor of stress intensity and propagation rate of a brittle crack are averaged values $\left(\overline{\mathrm{K}}_{\mathrm{iA}}\right.$ and $\left.\overline{\bar{V}}_{\mathrm{br}}\right)$, i.e. they are constant from the start moment till the stop of the of the brittle crack in the specimen, while the surface of a brittle fracture of the standard specimens are made up of several sections: the sections of starting to move and stop, and of rapid, steady and slow propagation of brittle crack[4] (fig.3).

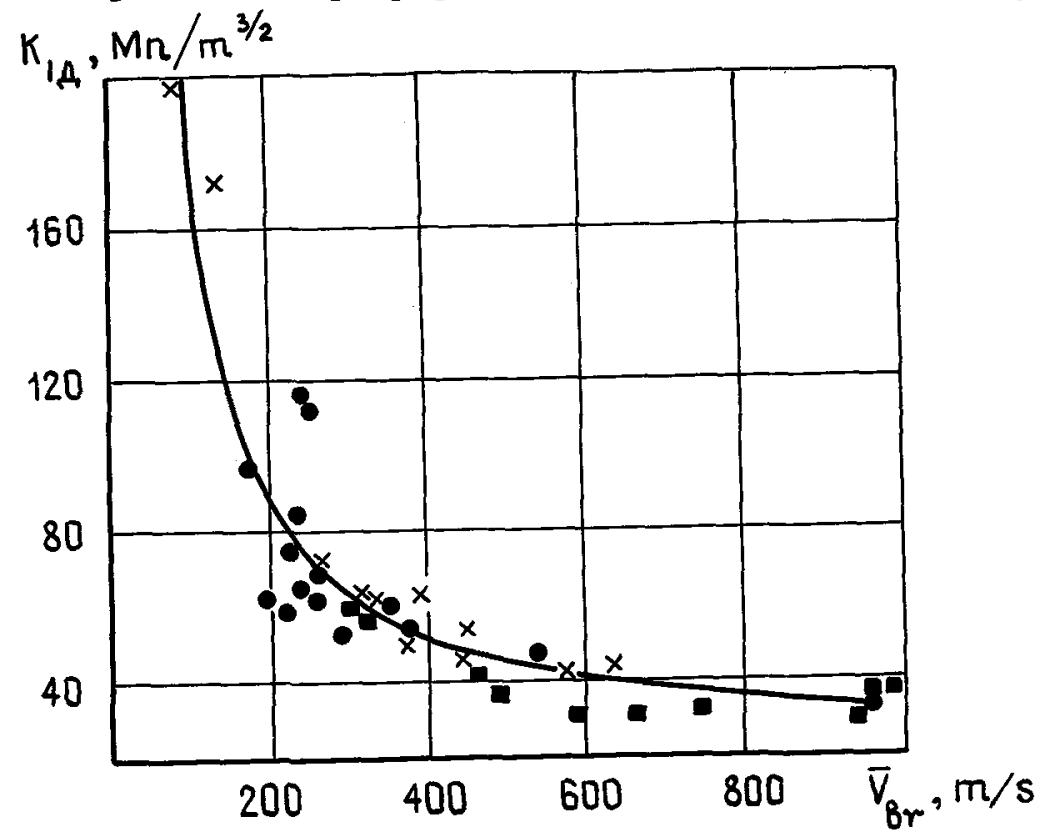

Fig.2. Dependence of the mean values of critical factors of stress intensity $\overline{\mathrm{K}}_{1 A}$ during the dynamic propagation of the brittle crack on its movement rate: $\mathrm{x},-$ steel $20 \mathrm{H}$ CM $\Phi$ if concentrators are along and across the roll; - steel 20 .

The statistical analysis of the fractograms of the brittle fracture surface shows that dimentions ( length and area) of the spall facets change towards the crack propagation direction and depend on the state of material brittleness, i.e. the propagation rate of a brittle crack. At the first stage of the crack propagation the spall facets dimentions increase, then they are stabilized and finally they start to decrease gradually. On the basis of this conclusion one can consider the brittle fracture surface made up from different sections(Table). 
The increase of spall facets dimentions is caused by material resistance decrease to brittle fracture, and the propagation rate of a brittle crack is proportonal to growth of spall facets dimentions. Hence, to determine the limit values of $K_{i A}^{p}$ and $v_{b r}^{p}$ during a brittle crack propagation one can use $\overline{\mathrm{K}}_{1 A}$ and $\overline{\mathrm{V}}_{\mathrm{br}}$ as initial characteristics represented in the form of relationships $\overline{\mathrm{K}}_{1 \mathrm{~A}}=\mathrm{f}\left(\mathrm{I}_{\mathrm{br}}\right)$ and $\overline{\mathrm{V}}_{\mathrm{br}}=\mathrm{f}^{1}\left(I_{\mathrm{br}}\right)$, and the statistical distribution of the fractographic indeces of the section surface of brittle fracture towards brittle crack propagation.

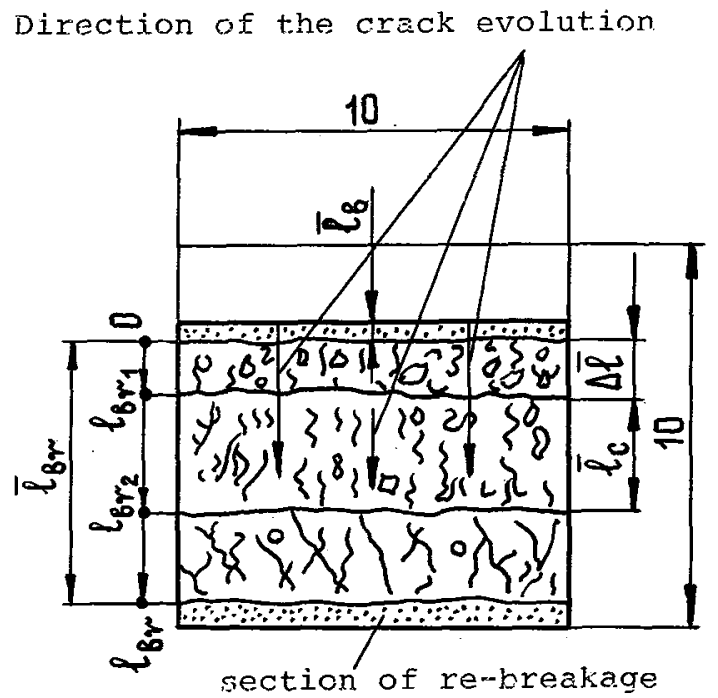

Fig.3. The scheme of the crack evolution in specimens.

It's valid to consider that its rate increases till $1_{\mathrm{brl}}$, and is constant between $l_{b r 1}$ and $l_{b r 2}$. Starting from $I_{\text {pr } 1}$ up to $I_{b r}$ it decreases and can be written as function $\mathrm{v}_{\mathrm{br}}^{\mathrm{p}}=\mathrm{f}_{2}\left(\mathrm{l}_{\mathrm{br}}\right)$, i.e. the character of function change $V_{b r}^{p}$ corresponds to the character of change of the fracture fractographic indeces towards the crack propagation.

From the constancy of energy expended on the brittle fracture of a breaking-off type and on the basis of areas equality restricted by functions $\bar{\nabla}_{b r}=f^{1}\left(I_{b r}\right)$ and $v_{b r}^{P}=f_{2}\left(I_{b r}\right), \bar{K}_{A_{A}}=f\left(l_{b r}\right)$ and $K_{1 A}^{p}=$ $\mathrm{f}_{1}\left(I_{\mathrm{br}}\right)$ one can obtain the following formulae for $\mathrm{V}_{\mathrm{br}}^{\max }$ and $\mathrm{K}_{\mathrm{I}_{\mathrm{A}}}^{\mathrm{min}}$ :

$$
\begin{aligned}
& V_{\mathrm{br}}^{\max }=\frac{1}{l_{B r}^{s t}}\left[\bar{V}_{B r} \cdot l_{B r}-\int_{0}^{l_{B r_{1}}} f_{2}\left(l_{B r}\right) d l_{B r}-\int_{l_{B r_{2}}}^{\ell_{B r}} f_{2}\left(l_{B r}\right) d l_{B r}\right] \\
& \mathrm{K}^{\min }=\frac{1}{l_{B r}^{s t}}\left[\bar{K}_{1 A} l_{B r}-\int_{0}^{l_{B r_{1}}} f_{1}\left(l_{B r}\right) d l_{B r}-\int_{l_{B r_{2}}}^{l_{B r}} f_{1}\left(l_{B r}\right) d l_{B r}\right]
\end{aligned}
$$

To estimate $V_{\mathrm{br}}^{\max }$ and $\mathrm{K}_{1 \mathrm{~A}}^{\mathrm{min}}$ it is necessary to find the integral values in $(3,4)$ by the character of change of fractographic indeces of fracture surface, and in particular by the change of statistic distribution of the area or the length of the spall facets towards the brittle crack propagation. 
The results of $\mathrm{V}_{\mathrm{br}}^{\max }$ and $\mathrm{K}_{\mathrm{IA}}^{\mathrm{min}}$ estimation show that in load testing of the standard specimens with $V$-shaped notch made from the low-alloy steel (C - 0,19\%, Si - 0,35\%, Mn - 1,0\%, Cr - 0,3\%, Ni - 1,0\%, Mo - 0,22\%, $\left.\mathrm{V}-0,11 \%, \sigma_{0,2}=471 \mathrm{MPa}, \sigma_{\mathrm{B}}=647 \mathrm{MPa}, \mathrm{KCV}_{2}=720 \mathrm{KJ} / \mathrm{m}^{2}\right)$ at $-40^{\circ} \mathrm{C}$ $\mathrm{V}_{\mathrm{br}_{\overline{\mathrm{x}}}}^{\mathrm{max}}=660,78 \mathrm{~m} / \mathrm{s}$ and $\mathrm{K}_{\mathrm{AA}}^{\mathrm{m} i n}=35,2 \mathrm{Mn} / \mathrm{m}^{3} / 2$, while $\overline{\mathrm{V}}_{\mathrm{br}}=546,1 \mathrm{~m} / \mathrm{s}$ and $\mathrm{br}_{\overline{\mathrm{K}}_{\mathrm{IA}}}=44,6 \mathrm{Mn} / \mathrm{s} \mathrm{m}^{3} / 2$.

Table 1. Change of fractographic indeces of fracture under test temperature lowering.

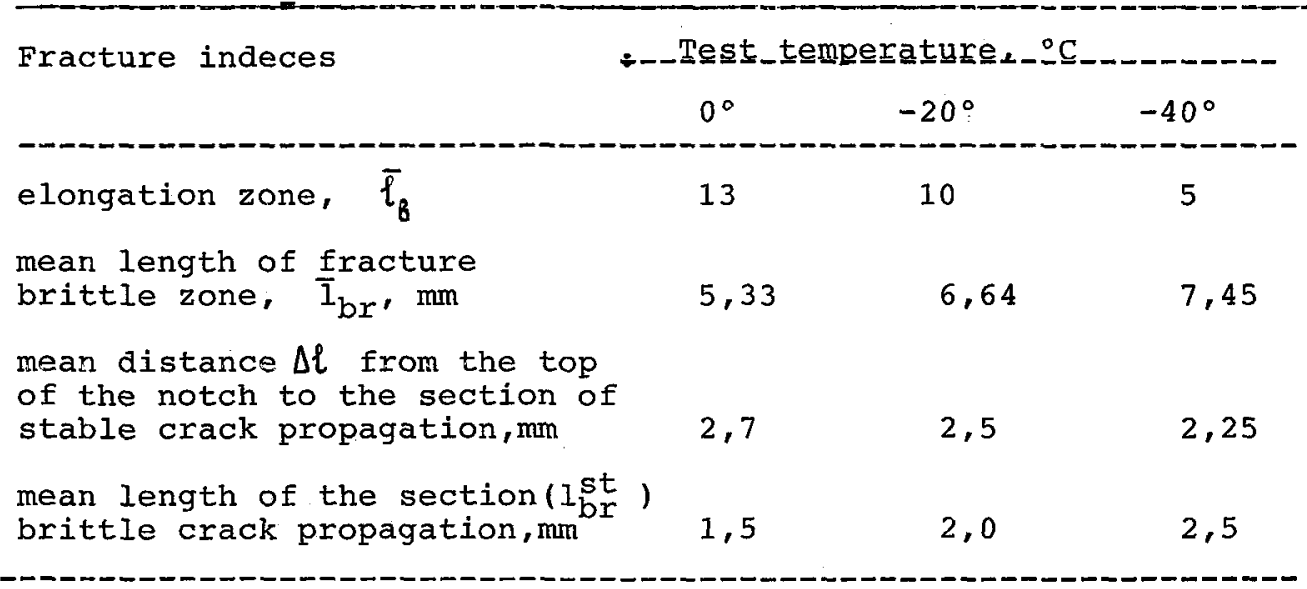

The complex analysis of $\mathrm{KCU}_{\mathrm{p}}, \mathrm{KCV}_{\mathrm{p}}$ - dependences on temperature and the ultimate values of $V_{b r}^{P}$ and $K_{P_{A}}^{p}$ determined by the $P-t$ or $P-V$ diagrams of the test and by the change of the distribution character of fractographic indeces of a brittle fracture surface of the standard specimens makes it possible to analyze the cold resistance of weld joints of metalwork units and Northern machinery. These criteria are the most sensitive to test temperature lowering and change of weld technology under the low climatic temperatures.

The control of the structure and mechanic properties of a weld and the stress-strain state of the weld joints as well by optimization of the technologic processes parameters can result in production of the cold resistance joints and improvement of operational strength of the weld structures designed to operate under theNorth extreme conditions.

On the basis of developed criteria requirements to cold resistance of steels and their weld joints the standard documents on optimization of the weld technology of steels for classes C 44/29, C 46/33,C 52/40, C $60 / 45, \mathrm{C} 70 / 60$ have been worked out by the authors.

\section{REFERENCES}

1. Procedure instructions. Calculations and strength tests. Methods of mechanical tests of metals. Determination of thefracture toughness characteristics (crack resistance) in dynamic loading. PD50 344-82, M.: edition of Standards, 1983. - 52p.

2. BULANENKO V.F., PYRUSSKY M.V. The temperature-rate relationship of resistance to dynamic brittle crack propagation // Factory lab. $1977, \mathrm{~N}=1 .-\mathrm{P} .91-95$. 
3. BASKO E.M., MAKHUTOV N.A. The investigation of crack resistance of building steels in dynamic simulation and brittle crack propagation // Factory lab. $-1981 .-N=4 .-P .66-70$.

4. LARIONOV V.P., AMMOSOV A.P.,ARGUNOVA A.A. Fracture fractograms relation to the crack propagation rate.-Information materials, is. 1(33). Kiev:Naukova dumka. 1988, P.18-22. 